\title{
On the design and monitoring of a master production scheduling function in a manufacturing resource planning environment
}

\author{
Citation for published version (APA): \\ Bertrand, J.W. M. (1983). On the design and monitoring of a master production scheduling function in a \\ manufacturing resource planning environment. In B. Wilson, C. C. Berg, \& C. French (Eds.), Efficiency of \\ manufacturing systems : proceedings of the NATO Advanced Research Institute, September 6-10, 1982, \\ Amsterdam (pp. 111-129). (NATO conference series. 2. Systems science; Vol. 14). Plenum Press.
}

Document status and date:

Published: 01/01/1983

\section{Document Version:}

Publisher's PDF, also known as Version of Record (includes final page, issue and volume numbers)

\section{Please check the document version of this publication:}

- A submitted manuscript is the version of the article upon submission and before peer-review. There can be important differences between the submitted version and the official published version of record. People interested in the research are advised to contact the author for the final version of the publication, or visit the $\mathrm{DOI}$ to the publisher's website.

- The final author version and the galley proof are versions of the publication after peer review.

- The final published version features the final layout of the paper including the volume, issue and page numbers.

Link to publication

\footnotetext{
General rights

- You may freely distribute the URL identifying the publication in the public portal. follow below link for the End User Agreement:

www.tue.nl/taverne

\section{Take down policy}

If you believe that this document breaches copyright please contact us at:

openaccess@tue.nl

providing details and we will investigate your claim.
}

Copyright and moral rights for the publications made accessible in the public portal are retained by the authors and/or other copyright owners and it is a condition of accessing publications that users recognise and abide by the legal requirements associated with these rights.

- Users may download and print one copy of any publication from the public portal for the purpose of private study or research.

- You may not further distribute the material or use it for any profit-making activity or commercial gain

If the publication is distributed under the terms of Article 25fa of the Dutch Copyright Act, indicated by the "Taverne" license above, please 
ON THE DESIGN AND MONITORING OF A MASTER PRODUCTION SCHEDULING

FUNCTION IN A MANUFACTURING RESOURCE PLANNING ENVIRONMENT

\author{
J.W.M. Bertrand \\ Department of Industrial Engineering and Management \\ Science \\ Eindhoven. University of Technology \\ P.O. Box 513 \\ $5600 \mathrm{MB}$ Eindhoven, Netherlands
}

\title{
INTRODUCTION
}

During the last decade, the theory and practice of production control have strongly developed under the influence of the availability of high speed computers, on the one hand, and Material Requirement Planning (MRP) as a planning tool for complex product structures, on the other hand. The use of computerized MRP techniques in the late sixties and early seventies triggered a process of reconsidering the structure of the production control system in an organization. This process, which is greatly supported by the American Production and Inventory Control Society (APICS), resulted the definition of an integrated set of basic production control functions and their mutual relationships. Elements in this structure are functions like demand management, production planning, resource planning, inventory control, final assembly scheduling, master production scheduling, material requirements planning, capacity requirements planning, input-output control and shopfloor control. The key element in this structure of production control functions is the Master Production Scheduling function (MPS). Figure 1, taken from Berry et a1., 1979, shows that part of the control structure that is directly related to the MPS function. According to the APICS definition, the MPS is defined as follows:

"For selected items, the MPS is a statement of what the company expects to manufacture. It is the anticipated build schedule for those selected items assigned to the master scheduler. The master scheduler maintains this schedule and, in turn, it becomes a set of planning numbers which "drives" MRP. ----". Furthermore: A master schedule item is an item that ---- would be deemed critical in terms of its 


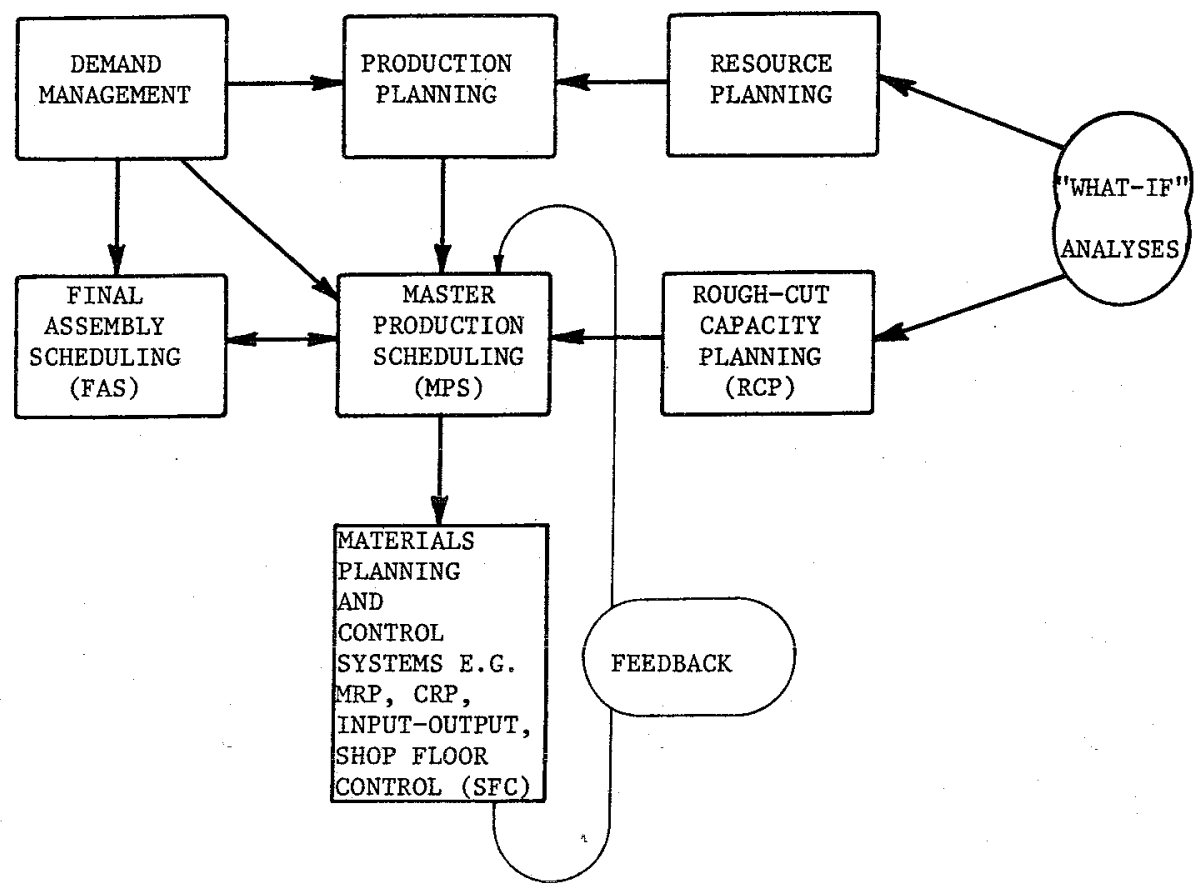

Fig. 1. Relationship of Master Production Scheduling to Other Manufacturing Planning and Control Activities 
impact on lower level components and/or resources, such as skilled labour, key machines, dollars, etc.---" (APICS, 1979).

The MPS is used to solve the conflicts between the market requirements on the one hand, and the production possibilities in terms of available resources and materials on the other hand, thereby taking into account the medium term guidelines set on a aggregate level in the Production Plan. Clearly, solving this conflict implies the balancing of planned levels of customer service, inventory, capacity variation, and capacity utilization. Therefore, in Fig. 1, the MPS function gets input from demand management, final assembly scheduling, rough-cut capacity planning, and a feedback input from material requirements planning. The balancing property in turn implies that the MPS function not only influences the delivery of MPS items, but also, implicitely, capacity loads, inventories, customer service and capacity variations. In fact, in terms of control theory, the MPS planning numbers can be considered as the instrument to exercize control - the control variables or decision variables - whereas customer service, inventory, capacity variation and capacity utilization are the goal variables - or the controlled variables - of the MPS function. In this view, the MPS function controls the production by specifying planning numbers for MPS items and planned capacity for production departments, which serve as an objective for the hierarchically lower level production control functions such as Logistics Control - the function that coordinates the release of workorders to the production departments - and Shop Floor Control.

Based on this view on the place of the MPS function in the production control system, we will determine requirements for the structure of the logistics control system, and the MPS process. Besides, we will develop a procedure for monitoring the performance of the MPS function. For this purpose we will use a conceptual framework borrowed from general control theory. A detailed discussion of this framework, and of its use for developing control and performance monitoring procedures in a production control environment, is given in Bertrand and Wortmann (1981). In the following section we will present a short overview of this framework. Thereafter we will analyse the logistic control function and the MPS decision procedure, and next we present the MPS monitoring procedures. In the final section conclusions are given.

\section{THE CONCEPTUAL FRAMEWORK}

We assume that a control problem can be described as follows: - a decision function exists,

= the decision function has norms, $N(t)$, for a set of goal variables, $\mathrm{D}(\mathrm{t})$,

- the decision function can manipulate a set of controllable variables (or decision variables), I(t),

- the goal variables are influenced by the controllable variables, 
- there exists a set of environmental variables, $E(t)$, which influence the goal variables, and which cannot be manipulated by the decision function, but can be observed by the decision function,

- the relationship between the controllable variables and the environmental variables, on the one hand, and the goal variables, on the other hand, is called the process to be controlled. This definition implies that the nature of the process follows from the definition of the goal variables and the controllable variables,

- if the process is dynamic, there exists a set of process state variables, $S(t)$. State variables are defined so that the behaviour of the goal variables during some time interval ( $t, t+d t$ ) is completely determined by the state at time $t$ and by the values of the inputs $I(t)$ and $E(t)$, during the time interval ( $t, t+d t)$,

- the decision function may receive information about the behaviour of the goal variables, the state variables and the environmental variables. The decision function may use, either implicitly or explicitly, a model of the environmental process, $\mathrm{M}_{\mathrm{e}}$, in order to produce predictions of future values of the environmental variables. Explanatory environmental variables, $H(t)$, which are used as external inputs in the prediction model, may then be defined. If the environmental process is dynamic in nature, then environmental state variables, $G(t)$, can be defined: in that case $M$ operates on $H(t)$ and $G(t)$. The relationship between $H(t)$ and $G(t)$, on the one hand, and $E(t)$, on the other hand, is called the environmental process, - the decision function uses, implicitly or explicitly, a model of the controlled process, $\mathrm{M}$, to evaluate possible decisions in the light of the norms, the actual values of the state and goal variables and, possibly, predictions about the environmental variables. Figure 2 presents the structure of a decision function according to these basic concepts. In the figure, I' $(t)$ represents possible decisions that are investigated with respect to their expected result $D^{\prime}(t)$, given the state of the process, $S(t)$, and given the expected values of the environmental variables, $E^{\prime}(t)$. Of course, the "what-if" character of the decision selection routine is used purely for illustration purposes. The decision function could also operate with a simple decision rule acting on $E^{\prime}(t)$ and $S^{\prime}(t)$, in which case the model is implicit - thus the models $M$ and $M$ need not be explicitly used in the decision procedure. However, bechuse in our view the models behind the procedures are the essence of the control, their presence is stressed in Fig. 2 .

Generally, the models $M$ and $M$ will not be perfect: not all variables influencing $D(t)$ or $E(t)^{P}$ in reality will be incorporated; their relationships may really be much more complex, the observations of the decision maker with respect to $H(t), S(t)$ and $G(t)$ may contain errors, and finally the decision that follows from the application of the formal decision procedure may not always be completely implemented, for various reasons. In this view on control processes, each of these different sources of uncertaintly constitutes a disturbance. The concept of disturbance comprises all factors that affect the predictive quality of the models $M_{p}$ and $M_{e}$. Furthermore, it includes 


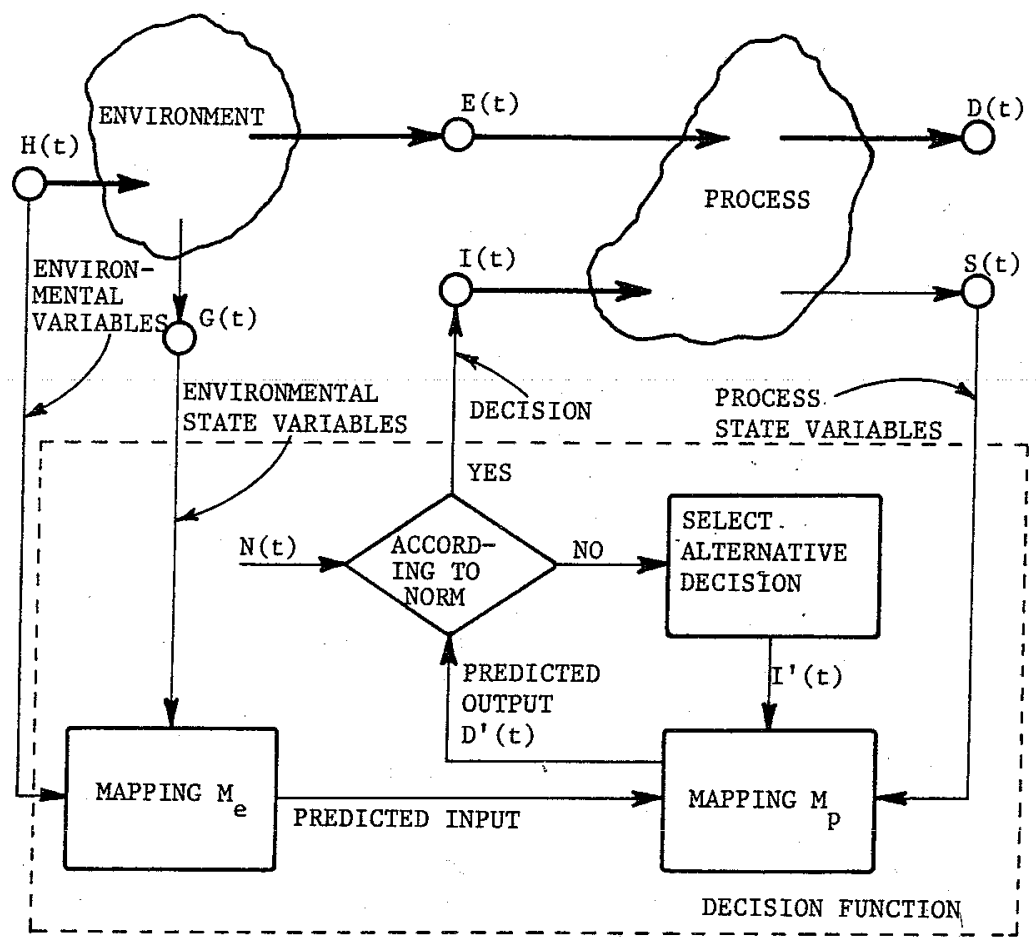

Fig. 2. The conceptual framework of a decision function.

errors in the information available for decision making and deviations that occur in the implementation of decisions. Thus the nature and the level of disturbance faced by a decision function is determined partly by the quality of the models used.

It will be clear that this view of control systems emphasizes the use of a model of the process to be controlled. However in practice a process model will not always be used explicitly in the decision produce itself. Often the decision procedure is a simple, easy to use, routine, with parameters determined from analysis of its performance in practice assuming that the real process is identical to the process model, possibly with some disturbance added to it. Nevertheless such a decision procedure is derived from a process model and it should not be mistaken for the use of an arbitrairy rule of thumb, which is not derived from an explicit process model. 
Because this process model in the first place serves as a basis for the design of the decision procedure, we will call it the design process model (DPM).

Now consider the situation where a decision procedure is used that has been derived from an explicit DPM. After some time, control performance may deteriorate with time. Therefore, it is important to monitor the control performance, and to be able to diagnose the cause(s) of a change, so that a founded redesign of the decision procedure is possible, if necessary. Changes may be due to external factors, but it may also be due to various causes inherent to the information and the procedures used by the decision function.

In the first place unnoticed changes may occur in the process to be controlled. As a result the quality of the DPM may deteriorate. This can be detected by monitoring the quality of the DPM. The process model quality can be monitored by feeding the DPM with the actual decisions, with the actual values of the environmental and state variables, to produce predictions of the goal variables. By comparing these predictions with the actual values of the goal variables, the error inherent in the model can be determined. An increasing error indicates a decreasing quality of the DPM.

Secondly, the formal decision procedure may contain errors (e.g. mistakes may have been made in the derivation of the decision procedure, which only results in poor control performance under specific circumstances). The existance of such an error can be established by feeding the DPM with:

- the values of the environmental and state variables as perceived by the decision maker, and

- the decisions which, for these values, would follow from the formal decision procedure

This results in predictions of the values of the goal variables, which should be compared with norms to evaluate the quality of the formal decision procedure. These norms should have been established in concert with the derivation of the formal decision procedure. If the predicted values deviate significantly from the norms, the decision procedure should be revised (provided of course that the quality of the DPM is sufficient, but this is tested seperately).

Thirdly and fourthly, the quality of the information and command channels requires monitoring. In principle, this can simply be done by direct comparison. However, in most practical situations such measurements will only be available with some delay and on an aggregate 1 evel.

Final1y, the conditions of the environment should be monitored. This requires that during the design phase the assumptions about the environmental operating conditions for the decision function have been specified, so that adequate monitoring procedures can be designed. 
The monitoring activities for the design process model, the decision procedure, the information quality and the command quality can be visualized in one scheme, together with the measuring of the control performance. This scheme is presented in Fig. 3.

From this scheme it will be clear that the presence of an explicit DPM is critical. If such a model is not available, direct evaluation of the performance of a decision procedure is not possible, not when selecting a decision procedure in the design phase, nor during the operation of the procedure. We conclude that selecting a proper DPM is a first requirement for the scientific design and functioning of a decision procedure. In the absence of a DPM, the formal decision procedure will be much more a "guess", or it may not even exist; that is, the decision maker may receive information about the current state of the process, but no decision advice based on a formal decision procedure. The decision maker then has to rely entirely on his mental model of the process.

\section{MASTER PRODUCTION SCHEDULING AS A CONTROL PROCESS}

For ease of discussion we consider a situation where a number of products are manufactures to stock, where each product is manufactures in a number of successive phases, with stock points in

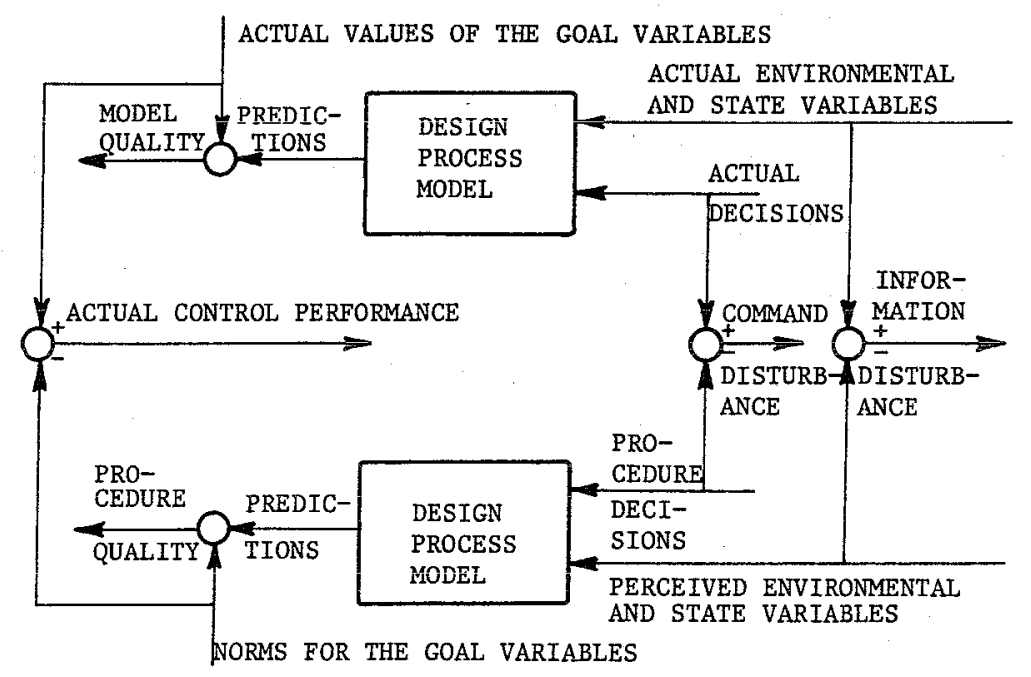

Fig. 3. The monitoring activities. 
between, and where production units are defined for each manufacturing phase. An example of such a situation would be a plant with assembly departments, subassembly departments and component manufacturing departments for a range of products. Production is controlled by releasing workorders for the manufacturing of batches of final products, subassemblies or components, and by placing purchasing orders at the suppliers. In broad lines, this situation is shown in Fig. 4.

In recent literature the function Final Assembly Scheduling is defined for the control of the final assembly workorders in reaction to actual customer demand (see Fig. 1). We will not follow this distinction in this paper, as this would complicate the discussion without making a real difference to our subject.

As stated previously, in terms of our conceptual framework the decision variables: of the MPS decision function are the set of planning numbers for each MPS item and the planned capacity per production department, and the goal variables are customer service, capacity variations, capacity utilization and inventory levels.

From Fig. 4 it will be clear that the MPS decision function has only an indirect influence on its goal variables. First, the logistics control function translates the MPS-numbers into planned workorder releases and short term capacity variations, and next, shopfloor control influences the actual flow of the workorders through the departments, leading to actual inventories, actual capacity loads and actual deliveries. According to our conceptual framework, the decision procedure of the MPS function should be based on a model of the causal relationships between its decision variable - the MPS planning numbers - and the behaviour of the goal variables. Thus the model used by the MPS decision function should contain assumptions, implicit or explicit, about the decision behaviour of the logistics control function and the shopfloor control function, and the results of their decisions for the flow of products.

(The same goes of course for the delivery control function. For convenience we will concentrate in this paper on the logistics control function).

From the above we conclude that to specify a DPM for the MPS decision function, we first should analyse the impact of the logistics control function on the flow of goods.

\section{Logistics Control}

The logistics control decision behaviour is not a standard routine. Although the broad lines of this decision behaviour are quite general, in detail it will differ for each specific production control situation. For the purpose of our paper however, we only need to consider the broad lines. Therefore we will develop a conceptual 


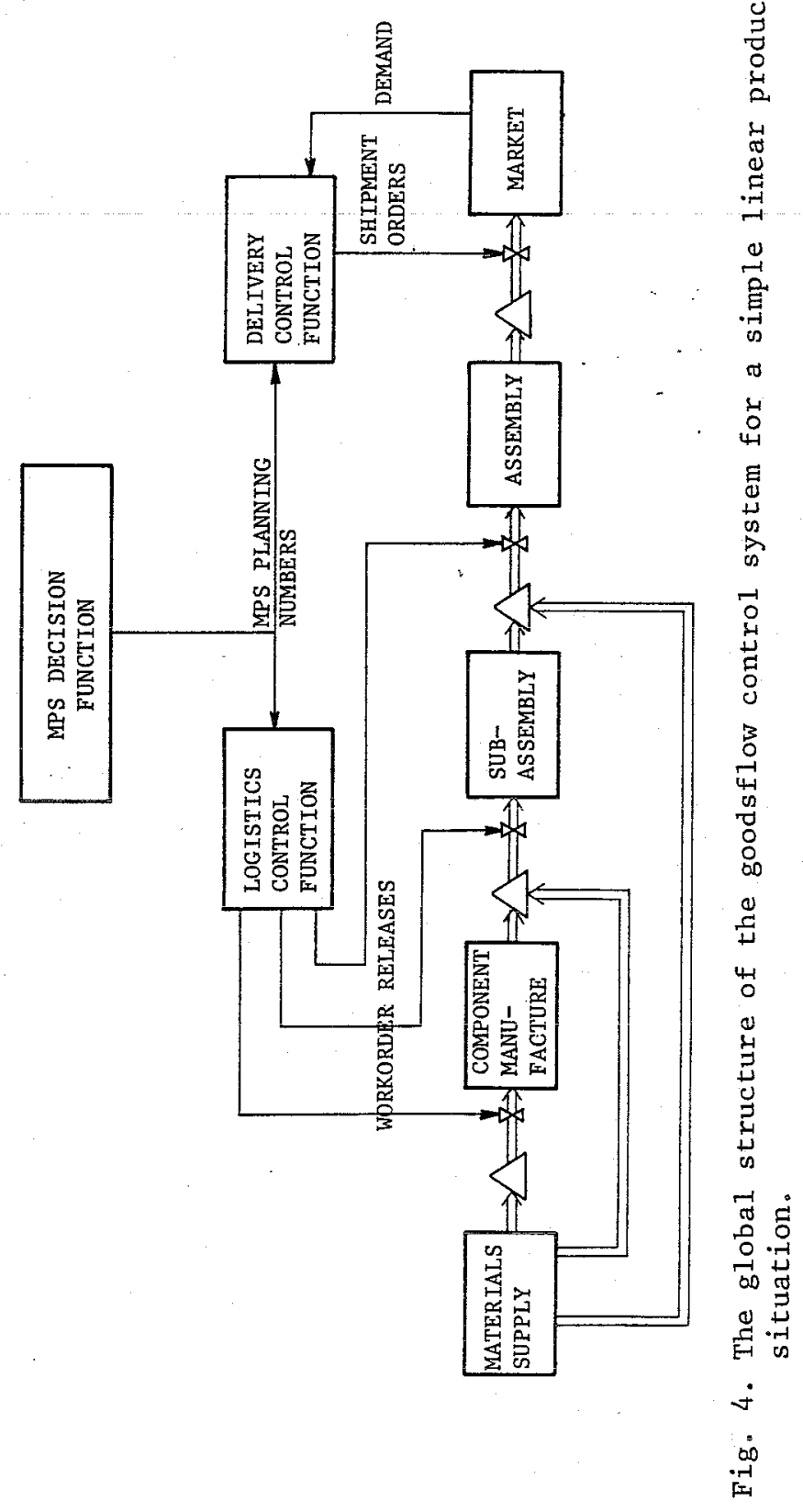


framework describing the required structure of this control layer between the MPS-decision system and the shop floor control systems, thereby building on the various control activities distinguished in modern literature.

In current literature on production control, (see Fig. 1) MRP techniques are proposed as a general tool for determining planned workorders from the MPS planning numbers. These planned workorders should be checked for materials availability, capacity availability and other constraints on the release of the workorders, modified to harmonize with the possibilities, and then put into action. The main aim of using this technique is to keep inventories as low as possible while maintaining a high level of customer order service.

One of the constraints on the release of workorders is given by the Input/Output Control (I/O Contro1) of the shop. Input/Output control techniques are used to control the workload of the department or the shop (see Fig. 1). The main aim of this technique is to keep the workload at the level where workorder throughput times per item are according to the norms used in the MPS and MPR procedures. Control of workorder throughput times is crucial, since all production control decision are based on assumptions regarding item lead-times, and workorder throughput times often contribute a considerable fraction of the total item lead-times.

Both of these techniques are a fine tool for their own purpose. However, we think that the decision process at the interface of these procedures should be distinguished separately. The decision process at the interface is extremely complicated, since various kinds of requirements and constraints on the planning and release of workorders should be simultaneously satisfied. Although the general nature of these requirements and constraints is known, the current theory does not contribute much to the structuring of this decision process. Therefore we will have to discuss this process in more detail first.

We assume that MPS decisions are taken each period, and that logistics control decisions are taken a number of times during that period, thus with a higher frequency than the MPS decisions. Consider the situation where the MPS planning numbers have been established and the logistics control starts its activities. First, for each item in the planning. Bill of Naterial (BOM), MRP will calculate the time phased workorders required to realize the MPS planning numbers, given work in process and inventories, batch sizes, yields and lead times. We call these workorders the MRP planned orders. The MRP planned orders may be unrealistic because of material shortages, capacity shortages or surplusses, sequencing constraints on the shop floor due to production economics, etc. This requires revision of the planning numbers before they can be used for workorder release. If these constraints are violated by the MRP planned orders, and there is no slack in the system to cope with these problems, then revision 
of the MPS-planning numbers is required (in Fig. 1 this process is indicated by the light feedback line). If this would happen frequently during the period, the control process would become very laborious, which in turn would slow down the speed of the decision process as a whole. Therefore we require that, in general, there should be enough slack in the system, as safety stocks and as short term capacity variations, to avoid the need for revisions of the MPS planning numbers during the period. The safety stocks and capacity slack provisions in the system should be based on this requirement. This also implies that at the start of each MPS decision process, the first thing to do is to make provisions for maintaining these slacks at their required level during each period. Only after this has been done, the real MPS decision process can be started, based on the remaining capacity and materials availability in the system.

Suppose that such a slack controlling procedure exists, and that the slack will be used by the logistics control function to solve the problems caused during each period by the MRP planned orders. (In MRP literature these problems are called "exceptions", which we think is a confusing term). Now we should notice that there are two types of problems. Firstly there are problems that can be solved by changing the order in which workorders are released to the shop. For instance, sequencing constraints on the release of workorders, short term material shortages due to unreliable deliveries etc. Solving these problems has only consequences for the planned orders up to a specific point in time. After that point the planning can remain as it was. Consequently, many of these problems will have no impact on the state of the inventories and work-in-process at the end of the period. Secondly, there are problems that can only be solved by shifting planned orders backward or forward in time over the entire planning horizon. For instance, rejects of materials, work-in-process, or inventories, will require the production of one or more items in the preceding phases to be speeded up or slowed down. Solving such a problem will have consequences for the planned orders over the entire horizon. As a result, the total required capacity during the remaining part of the period may deviate from the estimate made at the start of the period. The logistics control function might react to this by immediately changing the capacity and adapting the planned workorders. However, this would create quite nervous control behaviour, whereas it is not entirely clear to the logistics control function whether such immediate reaction is really necessary. For instance it might be that part of the planned production in the MPS has only been included to prevent short term machine idle time; the production may not be really needed on the short term. Another such effect is caused by the difference between the actual deliveries to customers during the period and the forecast made at the start of the period. Here we first have the problem of how to measure such a deviation if deliveries tend to be lumpy. However, even if deviations can be measured, the logistics control function does not a priori know how to react correctly to this disturbance of the planning. 
In fact to react properly to these types of disturbances it would be required to restart the MPS decision process. However, this implies that the MPS decision process would be a continuously ongoing activity, which is unmanageable in most practical situations.

This deadlock situation can be avoided by introducing an artificial requirement for the logistics control function. The requirement pertains to the amount of production per department to be realized during each period. The requirement states that production must be equal to the required production, expressed in capacity units of the critical capacity types, determined during the MPS decision process. During the period the logistics control function uses this required production level as an input to control the workorder release decisions. This could be done as follows. At the start of each period the required shopload is determined as the product of the required production level and the required workorder throughput times. During the period, workorders are released each time that the actual shopload drops below the required shopload (the shopload norm).

Which workorders are released, however, is determined by the current status of the planned workorders. The current planned workorders are determined as discussed earlier in this section: starting from the MRP planned orders, the planning is modified to account for the various types of disturbance encountered (the order of the orders is changed, lots may be split up or combined, orders of items are shifted backward or forward, etc.). Each time the shopload drops below the norm, the workorders with the earliest planned release dates are released, until the shopload is balanced again.

In this way the decision making on logistics control level has been split up into two parts:

- to determine whether workorders should be released;

- to determine which workorder should be released, taking into account external priorities ( $v i a \mathrm{MRP}$ ), and internal priorities and constraints.

For one of the production phases shown in Fig. 4, the relationships between the various decision functions discussed in this paragraph are presented in Fig. 5 .

\section{Master Production Scheduling}

We now are in a position to discuss the design process model for the MPS decision function. From the previous discussion it will be clear that in general the MPS decision function should take into account both capacity and materials availability in the system. It will furthermore be clear that the MPS decision function should exercise control at two levels. First, it should guarantee that sufficient slack will be available in the system, so that the logistics control function will be able to cope with the short term disturbances during the period. Second it should determine a MPS that 


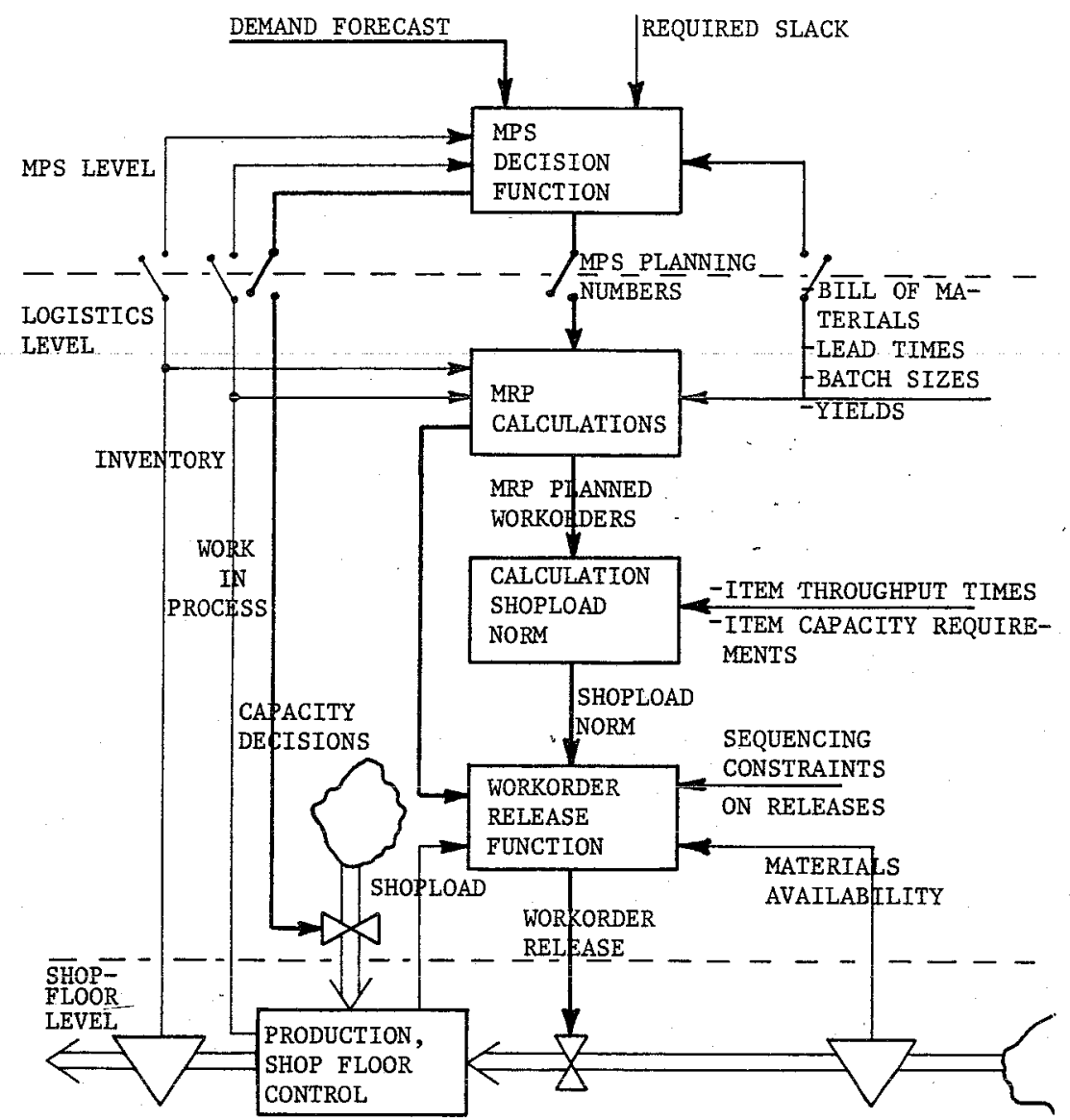

Fig. 5. The decision structure of the logistic control system in relation to its adjacent control levels, for a single production department.

meets the firm's objectives with respect to customer service, inventory costs, capacity utilization and capacity variation. As already mentioned previously, a DPM must be able to predict the response of the system output variables (or goal variables) to the inputs. For our situation, the inputs are the MPS planning numbers and the planned capacity (decision variables), yield deviations, and deviations of 
actual capacity relative to the plan (environmental variables). We could also demand that the model predicts the effects of short term disturbances, such as for instance delivery lead-time variations, and changes in the workorder release order relative to the plan. In that case these factors should also be defined as inputs to the design process model. However, it would be extremely difficult to model these effects, whereas we expect that it would not add much to the quality of the predictions. Therefore we will ignore these factors in the DPM. In the monitoring procedure, their effect on the goal variables will materialize as part of the deviations between real values and predictions (see Fig. 2) and thus contribute to the inaccuracy of the DPM. To cope with the effects of this inaccuracy (and other disturbances), a certain amount of slack is maintained in the system (see Fig. 5).

The calculation scheme constituting a possible MPS design process model for this situation is shown in Fig. 6. The scheme is the result of a first effort. We guess that more elegant models can be found. Nevertheless the scheme is satisfactory and it illustrates the use and properties of a DPM. The scheme consists of six basic modules, numbered 1 through 6 , which we will now shortly discuss.

- Module 1 consists of calculating the MRP-planned orders over a specific horizon from the MPS planning numbers, using a (possibly aggregated) planning BOM, and taking into account the starting ininventories and work in process in the system, after having made slack provisions for the next periods.

- Module 2 is used to adapt these MRP planned orders for product reject, yield deviations, and delivery deviations. How these adaptations must be made should be the subject of future research. Various procedures are possible here, which we will not discuss at this stage. Generally the adaptations will be non-existent if the model is used to support the MPS decision process. At that time, future deviations are not yet known. During the monitoring procedure however, these adaptations are necessary because the deviations will have had an impact on the workorder priorities in reality. Module 2 produces the sequence of the planned release workorders. The timing of these workorders still has to be adapted for available capacity.

- Module 3 uses Capacity Requirement Planning to determine the required production (in capacity units) over the horizon per department.

- Module 4 predicts the time-phased shopload in the departments, assuming that the logistics control function will use these required production levels as a basis for shopload control (see Fig. 5).

- Module 5 predicts the time-phased production (in capacity units) on the basis of the shopload and the time-phased available capacity. Depending on the type of shop (conveyor-belt assembly shop, Iine production shop, job shop etc.) various types of submodels can be used in this module. Discussion of these models is beyond the scope of this paper. Some knowledge is already available on 


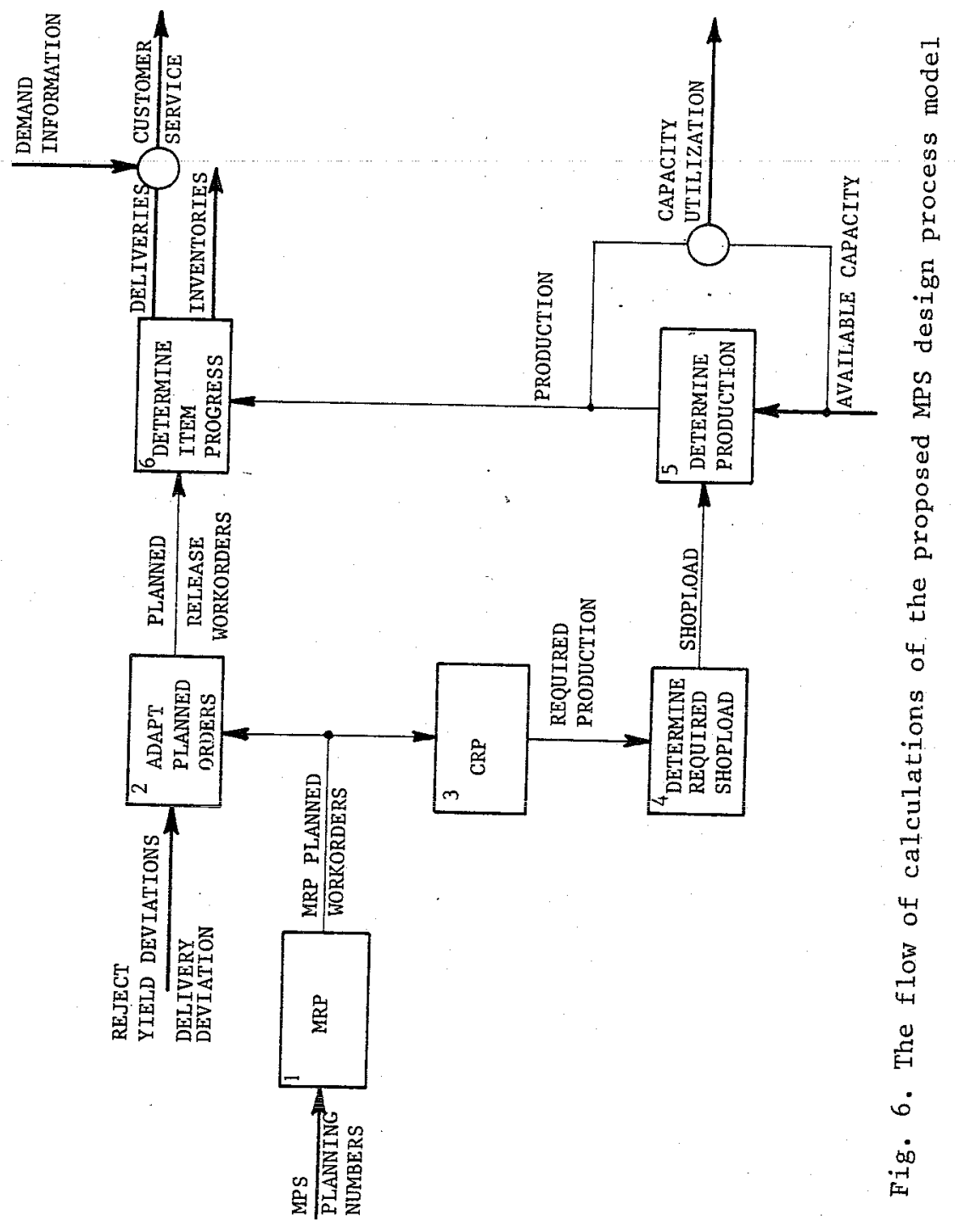


this subject (e.g. Solberg, 1981). However, much research is still required here.

- Module 6 uses the predicted production per department to determine the timing of the workorders, which sequence is given by the planned release workorders produced by module 2. Module 6 also yields predicted time-phased deliveries, and predicted inventory levels.

From the inputs and outputs of this set of modules the predicted values of the goal variables can be easily determined. The predicted capacity utilization follows from the predicted production and the available capacity, the customer order service follows from the customer order forecast and the predicted deliveries of end-products. Predicted inventories are directly available from the model, whereas capacity variations are directly related to the input variable "available capacity".

Suppose that the MPS decision procedure uses this type of DPM in a "what if" mode to predict the outcomes of possible configurations of MPS-planning numbers and capacity statements. Then the predicted outcomes should be evaluated in two respects:

- firstly, as widely stated in MPS literature, the MPS planning numbers must be realistic, that is, the time-phased deliveries of MPS items predicted by the model must be equal to the MPS planning numbers that served as an input to the model. Obviously, if the predicted deliveries are not equal to the delivery norm (the MPS) that drives the system, then the delivery norm is unrealistic (provided of course that the model is correct). We see that the use of an explicit DPM enables us to find an operational criterion for the requirement "the MPS must be realistic". With the usual techniques for evaluating a possible MPS, this is a problem;

- secondly, provided that the MPS is realistic, the predicted value of the goal variables must, be checked against the firm's policy regarding inventories, capacity utilization, capacity changes and customer service. An unacceptable predicted output leads to changes in the MPS or in the planned available capacity until a satisfactory combination is found. Of course, it may (and often will) happen that no combination can be found that exactly matches the firm's policy. Then, the best possible combination is selected, which results in specific deviations in the planned behaviour of the goal variables from their medium term norms. When evaluating the real performance of the control system afterwards, planned deviations should be distinguished from unplanned deviations, because different action may be required to reduce each of these types of deviation.

THE MONITORING PROCEDURES FOR THE MPS DECISION PROCESS

The best model available for the "what if" analysis in the 
MPS decision procedure is of course the DPM itself. However, in some situations this model may turn out to be too complex (too computer time consuming, too time consuming, or too difficult to handle in an interactive mode). Then, a simpler model may be used for the interactive "what if" analysis during the decision process. The detailed DPM can be used then each time after the decision has been taken, to check the quality of this decision. The assumption here is that the DPM is a correct representation of the controlled process. This checking process we called earlier "monitoring the quality of the decision procedure" (see Fig. 2). This process is shown in the lower part of Fig. 7. By monitoring the quality of the decision procedure after each MPS decision, serious errors in the decision procedure can be identified early, which may result in timely and adequate adaptations. Thus, this monitoring process creates a feedback-loop that maintains the quality of the decision procedure, relative to the DPM. Because this monitoring process can be performed off-line to the decision process, detailed and time consuming calculations are no problem since there is no severe time pressure on obtaining the results.

Finally, the quality of the DPM must be monitored. This is done at the end of each period, before the next MPS decisions have to be taken. Because the MPS planning numbers constitute a rolling schedule

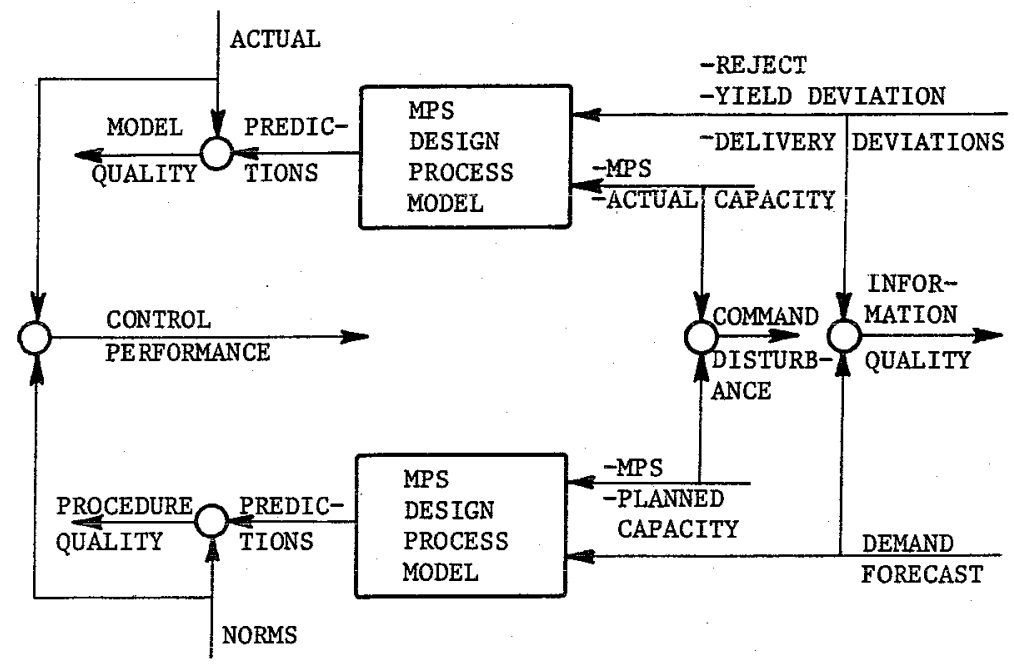

Fig. 7. The monitoring scheme for the MPS decision function. The predictions refer to the goal variables Utilization, Capacity, Customer Service and Inventory. 
which is updated at the start of each new period, only the one-period ahead prediction over the past period can be used to monitor the DPM. For each item and for each production unit, the predicted production and inventory based on actual values of the input variables are compared with the actual outputs. This process is shown in the upper part of Fig. 7. Analysis of the differences between prediction and reality may reveal deficiencies in the DPM, which may lead to timely adaptations of the model. Thus, this monitoring process creates a second feedback-loop that maintains the quality of the DPM relative to the reality it represents.

\section{CONCLUSIONS}

In this paper we have analyzed the Master Production Scheduling decision function and the Logistics Control Function from a control point of view. First, we have presented a conceptual framework, borrowed from general control theory, for structuring production control decision problems. The central point in this framework is the use of a formal model of the process to be controlled - a design process model. We have applied the framework to the analysis of the above mentioned functions, leading first to requirements for the structure of the Logistics Control function. Then we have identified a design process model for the MPS decision function, and from this we have determined the global structure of the MPS decision procedure. As a result we could operationally formalize the statement that "a MPS must be realistic". Finally we have identified the monitoring procedures both for the MPS decision procedure and the design process
model.

This paper once more reveals the importance of design process models for the design of control systems. However, much work still has to be done in applying these ideas to more complicated situations and in testing them in various practical situations. Nevertheless, we think that our results can serve as a firm basis for the design of MPS decision procedures. At the moment we are engaged in such a design process in practice.

\section{REFERENCES}

APICS, 1979, Capacity Planning and Master Production Scheduling, APICS Certification Program Study Guide, American Production and Inventory Control Society, Inc. Washington DC.

Berry, W.L., Vollmann, T.E., and Whybark, D.C., 1979, Master Production Scheduling, American Production and Inventory Control Society, Inc., Washington DC.. 
Bertrand, J.W.M. and Wortmann, J.C., 1981, Production Control and Information Systems for Component Manufacturing Shops, Elsevier Scientific Publishing Company, Amsterdam.

Solberg, J.J., 1981, Capacity Planning with a Stochastic Workflow Mode1, AIIE Transactions, 13,2 , pp. $116-122$. 